\title{
MONTE CARLO SIMULATION MODEL TO STUDY THE INEQUALITIES IN ACCESS TO EMS SERVICES
}

\author{
Bożena Mielczarek and Jacek Zabawa \\ Institute of Industrial Engineering and Management \\ Department of Computer Science and Management \\ Wrocław University of Technology \\ 50-370 Wrocław, Poland \\ Wybrzeże Wyspiańskiego 27 \\ E-mail: bozena.mielczarek@pwr.wroc.pl
}

\section{KEYWORDS}

Monte Carlo, Spreadsheet Simulation, Healthcare, Emergency Medical Services, Decision Support.

\begin{abstract}
A Monte Carlo simulation model has been set up to analyze the inequalities in access to emergency medical services (EMS) in Lower Silesia Region in Poland. In the former studies carried on by one author the differences between different evaluative criteria measuring the effectiveness of emergency system in the selected number of communes in one of the Polish South-West regions have been assessed. The goal of this paper is to examine, using a stochastic simulation Monte Carlo model, the influence of the predicted demographic changes (fluctuations of population number) and epidemiological changes (fluctuations in EMS events: calls-for-service passed to the dispatcher of EMS system) on the access to emergency care.
\end{abstract}

\section{INTRODUCTION}

Computer simulation has played a significant role in supporting health services managers in administrative, economical and medical decisions for many years. Many articles focusing on using simulation approach to the analysis of a wide spectrum of healthcare management problems have been reported in a number of scientific periodicals. The extensive taxonomy of the papers describing discrete-event simulation models addressing healthcare clinic problems up to 1997 was given in (Jun et al 1999). To determine the major up-todate healthcare areas supported by the simulation models, a survey of the literature focused on the articles published recently, in the last six - seven years, was conducted in (Mielczarek 2004). The exemplary, referenced models were developed by means of discrete-event simulation, system dynamics method (continuous simulation) and Monte Carlo technique. Five major area groups of applying simulation models to healthcare issues were defined: epidemiology, health care system operations, health and care systems design, medical decision making and crisis management ones. Models dealing with the managerial decision problems specific to emergency services may be found in all five distinguished groups.

Starting with the pioneering work of (Savas 1969) there has been extensive research on applying simulation approach to EMS issues. The most frequently studied problem is location/allocation analysis. Location analysis belongs to this EMS management decision area that directly influences timeliness and quality of service. The outcome of location decision is described by geographically based distribution of EMS resources, both static and mobile ones that will optimise some previously specified measurable criterion. The alternative arrangement of the ambulances in the departments may assure the better coverage of the region and the balanced utilisation of rescue teams.

The majority of the published models is built based on the discrete-event simulation approach. In EMS system, the calls-for-service appear in the system, and the system tries to satisfy the needs immediately or the call is withhold until the favourable conditions arise. Patient's appearance, ambulance arrival, the beginning of medical activities, transfer to the hospital, completion of service, theses are all examples of EMS discrete events. Discrete-event method is a powerful approach but it requires very detailed knowledge about the unit random processes describing the system's performance. In this article, the authors discuss the possibility of using Monte Carlo simulation method to examine the consequences of some demographic and epidemiological trends on the access to EMS system. The short review of basic findings of the previous study is given and then the key assumptions, general model outline and the initial results of the experiments are presented.

\section{BACKGROUND}

In Poland, emergency services are supplied by EMS stations to poviats (a poviat means a county that consists of some number of communes) and the contract values are funded according to the population number inhabiting the poviats. In (Mielczarek and Lubicz 2004) the inequalities in access to emergency medical services, based on evidence from Polish Lower Silesian region in the year 2003 were studied. The calls 
registered in four EMS stations located in Lower Silesia region (namely: stations $\mathrm{A}, \mathrm{B}, \mathrm{C}$ and $\mathrm{D}$ ) in the first 6 months of the year 2003 were analyzed, table (1).

Table 1: Number of Calls Registered in Four EMS Stations During 6 Months in 2003

\begin{tabular}{|c|c|}
\hline $\begin{array}{c}\text { EMS } \\
\text { station }\end{array}$ & Number of calls \\
\hline A & 1098 \\
\hline B & 1033 \\
\hline C & 1923 \\
\hline D & 4640 \\
\hline
\end{tabular}

Two evaluative criterions were used to assess the effectiveness of the system: response time $R T$ (time from the moment the call is collected by dispatcher until the moment the ambulance arrives on scene) and hospital transfer time HT (time from the moment the call is collected by dispatcher until the moment the patient receives the hospital treatment). The first one (RT) is given in the Polish Legal Act as the basic indicator of EMS system's effectiveness: the median of RT time need not exceed 8 minutes in urban and 15 minutes in rural area; the third quantyl of RT need not exceed 12 minutes in urban and 20 minutes in rural area. The second indicator (HT) is of the crucial meaning when estimating the time of reaching the hospital care. It is recognised that the maximal hospital waiting time shall not exceed 60 minutes (so called golden hour).

The basic findings of the previous work are as follows:

Finding no 1: As concerns the urban communes, response time (RT) oscillates around the values indicated in Legal Act but the service in rural areas is much worse - the recommended 15 minutes is significantly exceeded in two stations, figure (1), table (2): station C and D.

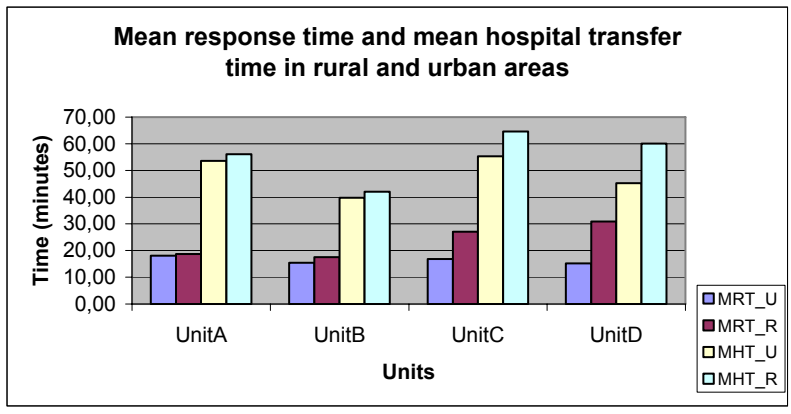

Figure 1: Mean Response Time (MRT) and Mean Hospital Transfer Time (MHT) in Rural (R) and Urban (U) Areas

Finding no 2: The good chances for not delayed hospital treatment have patients from only one station (B) and very bad prognosis may be formulated for patients living in the area of another station (C) where mean HT value and the median of HT exceed the recommended limit.
Finding no 3. Each station serves from a dozen or so to a few dozen of small administrative regions called communes. The analysis of discrepancies between actual demand (needs-for-service) and current supply (number of ambulances ready to serve the district) was conducted based on the RT and HT indicators separately for urban and rural communes. The comparison shows the considerably differences in the access to services provision among communes. The results of basic functional analysis were used to determine the clusters of communes "similar" in the sense of the service effectiveness (RT and HT times). Cluster analysis carried on for two-element vector (Mean RT and Mean HT) and calculated separately for every commune belonging to four stations, enabled to isolate four big clusters and two small two-element clusters, table (3). Each cluster gathers the communes from among all four stations and this reveals the high diversity in the access to EMS services by the people leaving in the same region. It shows the inappropriate allocation of both stationary and mobile resources inside the stations, which leads to the significant stratification of functional indicators between the communes. Clusters demonstrate also the inappropriate layout of the hospital wards. For example in Cluster no 4 there are communes having the small RT and at the same time the high HT.

Table 2: Mean Response Time (MRT) and Mean Hospital Transfer Time (MHT) in Rural (R) and Urban (U) Areas

\begin{tabular}{|c|c|c|c|c|c|c|c|c|c|c|}
\hline \multirow[t]{2}{*}{ 营 } & \multicolumn{2}{|r|}{ 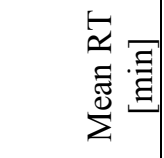 } & \multicolumn{2}{|c|}{ 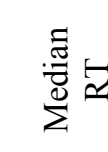 } & \multicolumn{2}{|c|}{ 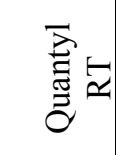 } & \multicolumn{2}{|c|}{ 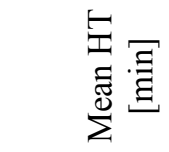 } & \multicolumn{2}{|c|}{ 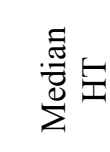 } \\
\hline & $\mathrm{U}$ & $\mathrm{R}$ & $\mathrm{U}$ & $\mathrm{R}$ & $\mathrm{U}$ & $\mathrm{R}$ & $\mathrm{U}$ & $\mathrm{R}$ & $\mathrm{U}$ & $\mathrm{R}$ \\
\hline $\mathbf{A}$ & 18,0 & 18,7 & 10 & 15 & 18 & 21 & 53,6 & 56,0 & 45 & 47 \\
\hline B & 15,4 & 17,5 & 6 & 14 & 13 & 20 & 39,7 & 42,0 & 31 & 38 \\
\hline $\mathbf{C}$ & 16,8 & 27,0 & 11 & 21 & 19 & 30 & 55,3 & 64,6 & 48 & 61 \\
\hline D & 15,1 & 30,9 & 8 & 20 & 17 & 38 & 45,2 & 60,1 & 39 & 46 \\
\hline
\end{tabular}

Table 3: Clusters' Characteristics

\begin{tabular}{|c|c|c|c|c|c|c|}
\hline \multirow{2}{*}{$\begin{array}{c}0 \\
z \\
\bar{y} \\
\tilde{v} \\
\underline{\Xi} \\
\bar{U}\end{array}$} & \multicolumn{3}{|c|}{$\begin{array}{l}\text { Number of } \\
\text { communes }\end{array}$} & \multirow{2}{*}{ 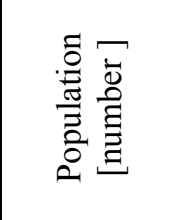 } & \multirow{2}{*}{ 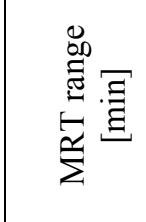 } & \multirow{2}{*}{ 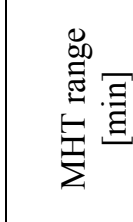 } \\
\hline & 吾 & 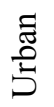 & 㞼 & & & \\
\hline 1 & 18 & 13 & 5 & 5229-1065252 & $5,2-14,7$ & $23,9-42,8$ \\
\hline 2 & 21 & 9 & 12 & \begin{tabular}{|c|}
$1868-128809$ \\
\end{tabular} & $10,0-22,4$ & $43,0-54,5$ \\
\hline 3 & 18 & 4 & 14 & $4071-9544$ & $18,2-26,5$ & $47,8-60,2$ \\
\hline 4 & 28 & 15 & 13 & $2313-13006$ & $12,2-32,4$ & $60,7-80,2$ \\
\hline 5 & 2 & 1 & 1 & & 27,$6 ; 35,8$ & 85,$9 ; 87,1$ \\
\hline 6 & 2 & 1 & 1 & & 37,$4 ; 36,8$ & 65,$7 ; 58,3$ \\
\hline
\end{tabular}




\section{MONTE CARLO APRROACH}

Monte Carlo is a recognized though not so extensively used approach in healthcare field as the discrete event method.

(Rauner et al. 2005) present a simulation model which enables to evaluate the economic effectiveness of diabetic foot prevention programs. Monte Carlo simulation was used to generate 10000 patients with a randomly distributed start-age and then the total number of diabetic foot complications was analyzed.

Static simulation model proposed by (Jacobson and Sewell 2002) enables to estimate random distribution parameters of maximal trade price of four types combined vaccinates protecting from six infectious diseases.

Coronary artery bypass grafts (CABG) take up greater part of funds appropriated for health care than any other basic medical procedure (Anderson et al. 2002). Simulation model using Monte Carlo technique and System Dynamics approach was worked out to estimate most essential factors determining cost and success of medical interventions. The simulation was run for random sample of 600 patients.

All those examples prove usefulness of Monte Carlo method and confirm the versatility of the approach in healthcare decision support field.

\section{MONTE CARLO SIMULATION MODEL}

Spreadsheet simulation model of EMS system was developed using Monte Carlo approach. The outcomes of previous studies served as the input data to simulation model developed in Microsoft Excel spreadsheet. We assumed that specific character of each commune (geographical relief, roads' conditions, ambulance station location, number and type of ambulances attached to each station, mortality and morbidity trends, etc.) let us determine Emergency Effectiveness Indicators (EEI1 and EEI2) for every commune. EEIs shall be interpreted as the determinants of the quality of service offered to the communes by the appropriate EMS station. EEIs are calculated based on the MRT (Mean Response Time) and MHT (Mean Hospital Transfer time) indicators determined empirically during the first phase of research studies as well as on the population number inhabiting the communes and the number of calls-for-service registered monthly in every commune on average. Next, the changes in demographic and epidemiological trends were simulated and their influences on the inequalities in access to EMS services were studied by Monte Carlo simulation model.

\section{Local population study}

Lower Silesian Voivodship is the southernmost Polish region. It occupies the $7^{\text {th }}$ position as regards the area and the $5^{\text {th }}$ as regards the population density. It is divided into 29 administrative units (poviats), which are further divided into 169 communes. The capital of the region is Wrocław. In the year 2003, emergency service was given by 12 EMS stations, having in total 60 emergency care ambulances and 37 resuscitation ambulances (so called "R"-ambulances) allocated to 67 EMS units. Specialist care was offered by 75 hospitals. 314827 emergency patients were given hospital care and among them the most significant group constituted the circulatory system cases (103 837) and accidents and poisoning cases (71 163).

The calls registered in four EMS stations (from among 12 in total: we will call the stations: A, B, C and D) in the first 6 months of the year 2003 were analyzed in order to calculate MRT and MHT indicators. Then the demographic and epidemiologic population data were matched with EMS data.

\section{Model logic}

The previous studies revealed that access to EMS services significantly differs for urban and rural areas. Simulations were then planned separately for each area type in the range of every poviat (administrative unit). Empirical analysis of the collected data (Mielczarek and Lubicz 2004) has also shown the considerably discrepancies in the access to services provision among communes. Authors intended to simulate the influence of the expected demographic changes (population growth/decrease taking into consideration the urban and rural areas) and forecasted epidemiological changes (calls-for-service growth/decrease taking into consideration severity type of the calls) on the inequalities in access to EMS services.

Simulation study was planned as follows:

- Calculating EEI1 and EEI2 indicators separately for every commune: the formula considers the population number inhabiting the commune, registered average monthly number of calls-for-service, previously determined Mean Response Time (MRT) indicator (considered for EEI1) and Mean Hospital Transfer time (MHT) indicator (considered for EEI2). The values of few exemplary EEI1 and EEI2 indicators are presented in table (4).

Table 4: Emergency Effectiveness Indicators (EEI1 and EEI2) Calculated for the Communes (exemplary data)

\begin{tabular}{|c|c|c|c|c|c|c|}
\hline $\begin{array}{c}\text { Com- } \\
\text { mune }\end{array}$ & $\begin{array}{c}\text { Popu- } \\
\text { lation }\end{array}$ & $\begin{array}{c}\text { Calls/ } \\
\text { month }\end{array}$ & $\begin{array}{c}\text { MRT } \\
{[\mathrm{min} /} \\
\text { call }]\end{array}$ & $\begin{array}{c}\text { MHT } \\
{[\mathrm{min} /} \\
\text { call }]\end{array}$ & $\begin{array}{c}\text { EEI1 } \\
{[\mathrm{min} /} \\
\text { pers. }\end{array}$ & $\begin{array}{c}\text { EEI2 } \\
{[\mathrm{min} /} \\
\text { pers. }\end{array}$ \\
\hline C1 & 31628 & 293,5 & 8,33 & 32,55 & 0,08 & 0,30 \\
\hline C2 & 35162 & 396,75 & 7,62 & 25,82 & 0,09 & 0,29 \\
\hline C3 & 9453 & 96,75 & 14,70 & 38,25 & 0,15 & 0,39 \\
\hline C4 & 7238 & 55 & 18,25 & 49,54 & 0,14 & 0,38 \\
\hline C5 & 6164 & 28,5 & 21,94 & 57,78 & 0,10 & 0,27 \\
\hline C6 & 6838 & 82,5 & 13,26 & 38,46 & 0,16 & 0,46 \\
\hline C7 & 6838 & 48 & 16,19 & 45,85 & 0,11 & 0,32 \\
\hline C8 & 16905 & 145 & 22,28 & 64,94 & 0,19 & 0,56 \\
\hline C9 & 4812 & 28 & 30,64 & 79,20 & 0,18 & 0,46 \\
\hline C10 & $\ldots$ & $\ldots$ & $\ldots$ & $\ldots$ & $\ldots$ & $\ldots$ \\
\hline
\end{tabular}


- Simulating the changes in population number inhabiting the poviats (distinguishing urban and rural areas). Taking into account the statistical data from the years 2003-2005, it was assumed that the changes will be of random nature from $-\mathrm{x} \%$ to $+\mathrm{y} \%$ (calculated separately for every poviat). The uniform distribution was used in the model with the ranges presented in table (5). Detailed demographic data availability was limited so the set of parameters for communes were derived from the data collected for poviats.

Table 5: Uniform Distribution Ranges for Demographic Changes in \% (for Exemplary Poviats)

\begin{tabular}{|c|c|c|c|c|}
\hline Poviat & \multicolumn{2}{|c|}{ Urban } & \multicolumn{2}{c|}{ Rural } \\
\hline & $\begin{array}{c}\text { Min } \\
{[\%]}\end{array}$ & $\begin{array}{c}\text { Max } \\
{[\%]}\end{array}$ & $\begin{array}{c}\text { Min } \\
{[\%]}\end{array}$ & $\begin{array}{c}\text { Max } \\
{[\%]}\end{array}$ \\
\hline P1 & $-0,61$ & $-0,29$ & 0,23 & 0,72 \\
\hline P2 & $-0,71$ & $-0,44$ & $-0,35$ & 0,09 \\
\hline P3 & $-0,76$ & $-0,33$ & 1,16 & 1,42 \\
\hline P4 & $-0,30$ & 0,06 & $-0,49$ & 0,08 \\
\hline P5 & $-0,67$ & $-0,31$ & $-0,36$ & 0,14 \\
\hline P6 & $-0,91$ & $-0,25$ & 0,22 & 0,68 \\
\hline P7 & $-0,59$ & $-0,32$ & $-0,24$ & 0,18 \\
\hline P8 & $-0,86$ & $-0,53$ & $-0,57$ & $-0,17$ \\
\hline P9 & $-0,43$ & 1,59 & $-0,89$ & 0,41 \\
\hline
\end{tabular}

- Simulating the changes in the number of calls-forservice. The data referring to daily and monthly calls' numbers during first 6 months of the year 2003 in the communes belonging to four selected stations (A, B, $\mathrm{C}$ and $\mathrm{D})$ were analyzed. Based on these calculations the ranges for random fluctuations were defined. Table (6) presents the exemplary distribution ranges for one (exemplary) Urban and one (exemplary) Rural commune.

Table 6: Exemplary Distribution Ranges for Number-ofCalls in Urban (C59) and Rural (C64) Commune (Data for Two Exemplary Communes)

\begin{tabular}{|c|c|c|c|}
\hline Commune & Min & Max & Average \\
\hline C59 & 123 & 191 & 145 \\
\hline C64 & 33 & 58 & 41 \\
\hline$\ldots$ & $\ldots$ & $\ldots$ & $\ldots$ \\
\hline
\end{tabular}

- Performing 200 replications separately for every commune.

- Predicting MRT and MHT values out of simulation experiments, taking into account the changes in demographic trends, the fluctuations in the needs for emergency treatment and the stability of EEIs indicators.

- Calculating 95\% confidence intervals for predicted MRT and MHT indicators determined in the simulation for randomly generated number of calls- for-service and randomly modified population number.

\section{Experiments and results}

Simulation assumes the stability (in short time) of the EEIs indicators calculated based on the empirical data. The changes in population number and the uncertainty about the average number of calls-for-service were modeled with the random distributions. During this phase of the studies we assumed that uniform distribution is a good approximation of the phenomenon. Figure (2) shows the screenshot of the model presenting two exemplary communes (C59 and C64) belonging to station $\mathrm{C}$. One commune (C59) has the indicators MRT and MHT on a satisfactory (low) level, while the other commune (C64) is characterized by worse level of service (higher values of MRT and MHT indicators).

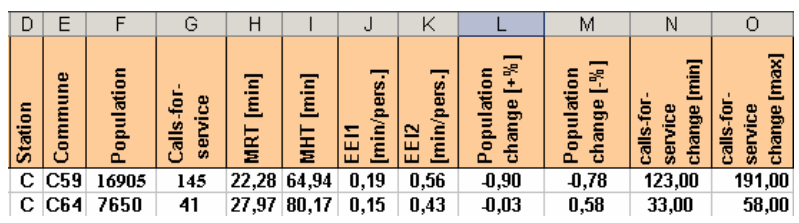

Figure 2: MS Excel Spreadsheet with a Fragment of Data Module

The results from running the simulation (200 replications for every commune, figure (3)) show the variability in the effectiveness indicators measured by Mean Response Time (MRT) and Mean Hospital Transfer time (MHT) and assuming the stability of Emergency Effectiveness Indicators (EEI).

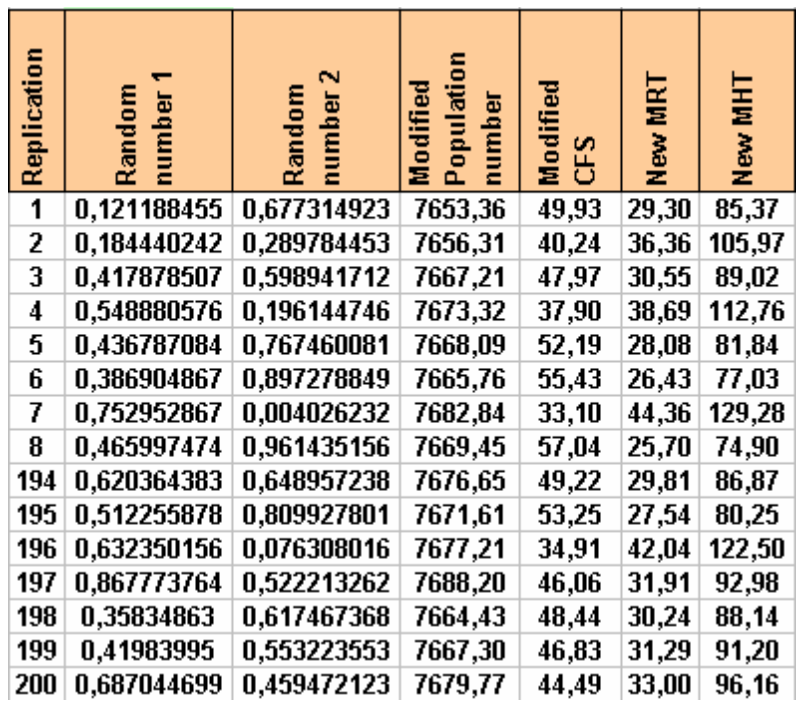

Figure 3: MS Excel Spreadsheet with a Fragment of Simulation Module Presenting 15 of 200 Replications for Commune C64

The uncertainty of the predictions arises from the randomness of the calls-for-service arrivals and the 
variability of population number. The $95 \%$ confidence interval indicates that the new results of MRT and MHT generated from the simulation will have a $95 \%$ chance of lying within the interval, c.f. figure (4).

\begin{tabular}{|l|c|c|}
\hline Urban C59 & \multicolumn{3}{|c|}{ New MRT New MHT } \\
\hline Average & 20,39 & 59,43 \\
\hline Std. Var. & 2,63 & 7,66 \\
\hline Halth Width & $\mathbf{0 , 0 1}$ & $\mathbf{0 , 0 3}$ \\
\hline Low range & 20,38 & $\mathbf{5 9 , 4 0}$ \\
\hline High range & 20,40 & 59,46 \\
\hline & \multicolumn{3}{|c|}{} \\
\hline Rural C64 & New MRT New MHT \\
\hline Average & 32,81 & $\mathbf{9 5 , 6 3}$ \\
\hline Std. Var. & $\mathbf{5 , 1 0}$ & $\mathbf{1 4 , 6 7}$ \\
\hline Halth Width & $\mathbf{0 , 0 2}$ & $\mathbf{0 , 0 7}$ \\
\hline Low range & $\mathbf{3 2 , 7 9}$ & $\mathbf{9 5 , 5 6}$ \\
\hline High range & $\mathbf{3 2 , 8 4}$ & $\mathbf{9 5 , 6 9}$ \\
\hline
\end{tabular}

Figure 4: Predicted MRT and MHT Indicators with 95\% Half Width Interval

It is too early to make strong forecasts, but based on the initial experiments, it is clear that the inequalities in access to EMS service will deepen assuming the same mode of funding the contract values. The well served communes will receive better treatment in the future (the indicators will improve), while the communes with more difficult access to EMS service will experience further deterioration in the quality of service, figure (5).

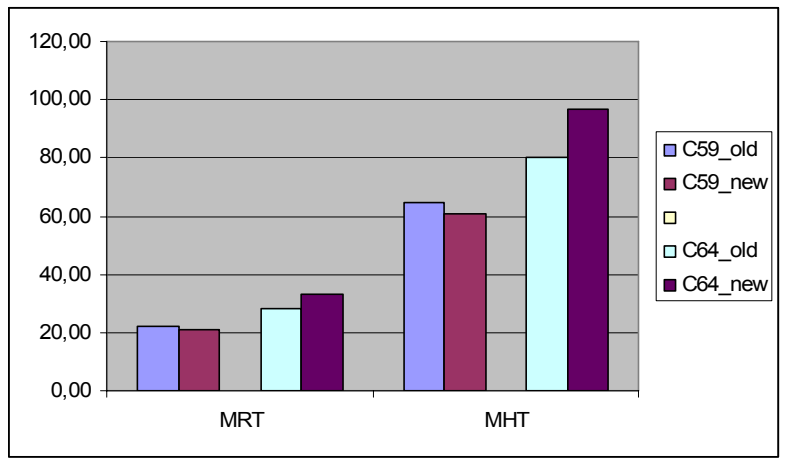

Figure 5: Empirical Values (old) and Predicted from Simulation (new) of MRT and MHT Indicators

\section{CONCLUSIONS}

The research confirms the necessity to go deeply into the analysis concerning the reasons of so significant discrepancies in access to EMS services by people living within the region of one station. The authors propose simulation method, which proved to be a significant tool in the analysis of a wide variety of healthcare delivery systems. Simulation approach enables to study the less structured decision problems, which can not be investigated by analytic models. Simulation is able to predict the changes in effectiveness of EMS system. It provides information about the uncertainty of these projections based on random calls-for-service arrivals and probability distributions of population changes. In particular it might be useful in the so-called location/allocation problems. Simulation may be used to test any configuration of real system as regarding both stationary and mobile resources. The information received when uniting communes into clusters may be used to simulate the alternative arrangement of the ambulances between the stations in such a way that will assure the better coverage of the region (the shorter response time), the balanced utilisation of rescue teams, the shorter hospital transfer time and the more even access to EMS services by populations inhabiting different communes.

Authors chose Monte Carlo method which is a simple but powerful technique enabling to incorporate the uncertainties into the model quite easily. Monte Carlo method is used to model the processes too complex to be solved by analytical approaches. The main feature of the method is the sampling of random numbers and then transforming them into random distribution defined before based on the empirical (historical) data.

Authors plan to conduct the complete model validation, in particular - historical validation. For this purpose, the empirical data from another year is being collected. The authors are going to enhance the model by creating the module simulating the severity of the calls, enabling to divide the calls into urgent and non-urgent cases. The Polish EMS system is now in the state of crucial transformation (new Legal Act has just started to be in force), so it would be interesting to verify the model also for the modified external conditions.

\section{REFERENCES}

Anderson, J.G.; W. Harshbarger; H.C. Weng; S.J. Jay; and M.M. Anderson. 2002. "Modeling the Costs and Outcomes of Cardiovascular Surgery". Health Care Management Science 5, 103-111.

Jacobson, S.H. and E.C. Sewell. 2002.'Using Monte Carlo Simulation to Determine Combination Vaccine Price Distributions for Childhood Diseases". Health Care Management Science 5, 135-145.

Jun, J.B.; S.H. Jacobson; and J.R. Swisher. 1999. “Application of Disrcete-Event Simulation in Health Care Clinics: a Survey". Journal of Operational Research Society 50, 109-123.

Mielczarek, B. and M. Lubicz. 2004. "Optimal Resource Planning of Emergency Medical Service. The Benefits of Simulation Approach in Coverage Decision Making". In Proceedings of 8th International Conference System Science in Health Care Geneva 2004, (Geneva, Switzerland, Sept 1-4. Session Decision Making 2, CD.

Mielczarek, B. 2004. "Symulacja Komputerowa jako Narzędzie Wspomagania Decyzji w Ochronie Zdrowia”. In Symulacja systemów gospodarczych. Część II 2004, A. Balcerak and W. Kwaśnicki (Eds.) Poland, Wrocław, 159181

Rauner, M.S.; K. Heidenberger; and E.M. Pesendorfer. 2005. „Model-based Evaluation of Diabetic Foot Prevention Strategies in Austria". Health Care Management Science 8, 253-265. 
Savas, E.S. 1969. "Simulation and Cost-effectiveness Analysis of New York's Emergency Ambulance Service”. Management Science, 15(12)

\section{AUTHOR BIOGRAPHIES}

BOŻENA MIELCZAREK was born in Poland and went to Wrocław University of Technology, where she studied management science and obtained her degree in 1984. She works as an assistant professor in the Computer Science and Management Department at WUT. She holds a PhD in Economics (in the field of Management Science) from Wroclaw Technical University. Her research includes decision support (particularly stochastic simulation modeling) in health care management. Her e-mail address is: bozena.mielczarek@pwr.wroc.pl and her Web-page can be found at http:// www.ioz.pwr.wroc.pl/Pracownicy/Mielczarek

JACEK ZABAWA was born in Poland and went to Wrocław University of Technology, where he studied computer technology. He obtained his degree in 1994 and then his Ph.D. in the field of management science in 2005 at Institute of Industrial Engineering and Management where he is employed. His e-mail address is: jacek.zabawaepwr.wroc.pl and his Web-page can be found at http:// www.ioz.pwr.wroc.pl/Pracownicy/Zabawa 